\title{
AN EMPIRICAL ANALYSIS OF THE IMPACT OF INFORMATION CAPABILITIES DESIGN ON BUSINESS PROCESS OUtsourcing PERformance ${ }^{1}$
}

By: Deepa Mani

Indian School of Business

Hyderabad 500032

INDIA

Deepa.Mani@isb.edu

\author{
Anitesh Barua \\ McCombs School of Business \\ University of Texas at Austin \\ 1 University Station, B6500 \\ Austin, TX 78712 \\ U.S.A.
}

Anitesh.Barua@mccombs.utexas.edu

Andrew Whinston

McCombs School of Business

University of Texas at Austin

1 University Station, B6500

Austin, TX 78712

U.S.A.

abw@uts.cc.utexas.edu

\section{Abstract}

Organizations today outsource diverse business processes to achieve a wide variety of business objectives ranging from reduction of costs to innovation and business transformation. We build on the information processing view of the firm to
\end{abstract}

\footnotetext{
${ }^{1}$ Dorothy Leidner was the accepting senior editor for this paper. Ravi Bapna served as the associate editor.
}

theorize that performance heterogeneity across business process outsourcing (BPO) exchanges is a function of the design of information capabilities (IC) that fit the unique information requirements (IR) of the exchange. Further, we compare performance effects of the fit between IR and IC across dominant categories of BPO relationships to provide insights into the relative benefits of enacting such fit between the constructs. Empirical tests of our hypotheses using survey data on 127 active BPO relationships find a significant increase (decrease) in satisfaction as a result of the fit (misfit) between IR and IC of the relationship. The results have implications for how BPO relationships must be designed and managed to realize significant performance gains. The study also extends the IPV to identify IC that provide the incentives and means to process information in an interfirm relationship.

Keywords: Business process outsourcing, governance, performance, information requirements, information capabilities, information processing view

\section{Introduction}

Business process outsourcing (BPO) refers to the delegation of one or more information technology enabled business processes to an external service provider (Rouse and Corbitt 2006; Wülenweber et al. 2008). Business processes involve the manipulation of either physical or informational objects (Davenport and Short 1990). Outsourcing of the former constitutes contract manufacturing and is distinct from BPO. Thus, in this study, business processes comprise a series of interrelated activities that exchange or transform input infor- 
mation to create value. IT is integral to process execution and management in BPO. This is true of transactional processes such as administration or processing services, where IT performs simple automation or process updates, as well as more strategic processes such as customer analytics or financial planning, where IT facilitates linkages with other processes and delivers business information to process workers in a timely fashion.

Given its dependence on IT, BPO shares important attributes with information technology outsourcing (ITO). Yet, there are important distinctions between these two outsourcing forms, namely, the objectives driving the outsourcing decision. Prior research (e.g., Lacity and Willcocks 2001; Wüllenweber et al. 2008) and industry surveys attribute the adoption of ITO to two primary factors: a focus on core competencies of the firm and reduction of IT costs. On the other hand, BPO involves significant diversity in outsourcing objectives, ranging from reduction in operating costs to innovation and business transformation (Linder et al. 2002). This range of BPO objectives reflects significant heterogeneity in the nature and strategic context of outsourced business processes.

As a consequence of this heterogeneity, each business process must be analyzed based on its underlying attributes. A business process is unique in its analyzability (e.g., high and low analyzability of tax management and customer experience management respectively), dynamism (e.g., high and low dynamism of product development and payroll processing respectively), or interdependence with other organizational processes (e.g., high and low interdependence of financial planning and new credit card issuance respectively). These attributes, in turn, engender significant heterogeneity in the amount and frequency of information change that must be managed on an ongoing basis. For instance, processes such as benefits management or new credit card issuance are characterized by fewer and predictable information changes in the task environment. However, the execution of more strategic processes that involves direct interactions with customers in the downstream value chain (e.g., marketing campaign management), with suppliers in the upstream chain (e.g., logistics management), and with employees in support operations (e.g., training, financial planning) is characterized by more unpredictable information changes. Further, timely access to relevant information is critical in these interactions (e.g., access to billing information in addressing a customer query or access to sales and research and development information in new product development). A key premise of this study is that this unique nature of the outsourced process and its ensuing information needs are critical to developing prescriptions for $\mathrm{BPO}$ management.
Prior theoretical and empirical work on ITO management and performance, while providing a rich starting point to develop a model of BPO performance, is characterized by an important limitation: the specific nature of the outsourced task receives little attention (Dibbern et al. 2004). Performance hinges on addressing appropriation concerns that arise from behavioral uncertainty perceived by the user firm about its relationship with the provider through contract design (Kern 1997; Willcocks and Kern 1998) or social exchange aspects such as trust and its underlying normative behaviors that act as self-enforcing safeguards (Grover et al. 1996; Marcolin and McLellan 1998). ${ }^{2}$ These studies largely draw on transaction cost economics, agency theory, or social exchange theory to develop their arguments (Dibbern et al. 2004).

Yet, as we noted earlier, the very nature of the outsourced process requires attention in BPO. Bounded rationality, in addition to limiting the user firm's capacity to predict provider intent, also limits its ability to anticipate information changes in the outsourced process or formalize actions to respond to such change. The difference between adaptation problems engendered by relational and process uncertainty is understood in the strategy literature in terms of the difference between aligning interests (cooperation) and aligning actions (coordination) (Gulati et al. 2005; Heath and Staudenmayer 2000; Jacobides 2005). ${ }^{3}$

This study takes into account the nature of the outsourced process by exploring the performance of BPO relationships through the lens of information processing. The information processing view of the firm (IPV) (Galbraith 1973) characterizes firms as information processing networks with limited information processing capacities that are faced with different levels of uncertainty in their task environments. The objective of the firm is to design the right structure that facilitates the right amount of information needed to cope with task uncertainty and achieve desired performance. The focus of the IPV on task uncertainty as a basis for organization offers a sound means to capture the unique information requirements

\footnotetext{
${ }^{2}$ Dibbern et al. (2004) find that the emphasis on these relational aspects is often to the exclusion of the contractual structure. This is likely because the relationship theories that form the basis for some of these studies contend that formal contracts may signal distrust of the exchange partner and, by undermining trust, encourage, rather than discourage, opportunistic behavior (Fehr and Gachter 2000; Ghoshal and Moran 1996).

${ }^{3}$ These studies explain that problems of cooperation arise from incentive conflict. However, problems of coordination arise due to the lack of shared knowledge about the "decision rules that others are likely to use" (Gulati et al. 2005, p. 419) and mutual interdependencies. Thus, the latter have their origin in cognitive conflict.
} 
of the outsourced process, which, in turn, determine the managerial challenges in the relationship and, hence, the information capabilities required for ongoing coordination of process decisions and tasks across firm boundaries. Thus, the IPV allows us to extend the focus of prior outsourcing research on the mutual exchange of rights to include the mutual exchange of information.

Building on research in the IPV tradition (Galbraith 1973; Tushman and Nadler 1978), we theorize that managerial effort in BPO involves the design of information capabilities (IC) that manage the idiosyncratic information requirements (IR) of the outsourced process ${ }^{4}$ in addition to appropriation concerns. Thus, we expect that user firms will design IC that fit the IR of the BPO relationship. Further, user firms can expect significant performance gains from such effort. Tests of our hypotheses using survey data on 127 BPO relationships confirm that performance differences across BPO relationships arise as a function of the fit between the IR and IC of the exchange.

The primary contribution of our study is to BPO theory and practice. The study of BPO is salient to information systems researchers for three reasons. First, given that IT is integral to process execution and management in BPO, the IS field is best positioned to leverage its knowledge of IT management to enhance process management in BPO. This argument is consistent with the view of Dibbern et al. (2004) that evolving forms of outsourcing offer an important opportunity to the IS field.

Second, industry and academic research (e.g., Borman 2006) suggests that with the growing maturity of the ITO market, ITO is increasingly being bundled with BPO offerings and subsumed into a broader business process decision. According to Gartner, the delivery of such converged ITO/ BPO services is expected to account for over 40 percent of the total deals by revenue by 2010 . They emphasize that, moving forward, an understanding of the issues unique to BPO management is essential for the IT organization. Emergent academic literature in IS also recognizes this trend and recommends that IS outsourcing research move beyond the boundaries of the IS function to include entire information technology enabled business processes (Hirschheim et al. 2008).

\footnotetext{
${ }^{4}$ While the focus of this study is on process uncertainty and IR, we include a series of controls that account for uncertainty in the BPO relationship and allied appropriation concerns or incentive conflicts that must be managed. Further, our conceptualization of IC of the BPO relationship includes structures, processes, and technologies that address both relational and process uncertainty.
}

Third, BPO is an example of how advances in IT are rendering business capabilities more portable so that even core processes like $R \& D$, marketing, or financial planning are moving outside the firm and changing the way firms' value chain decisions shape their competitive position. Agarwal and Lucas (2005) contend that the future of the IS field depends on researchers undertaking research on macro topics that represent the transformational impact of IT.

Despite the salience of BPO research to the IS field for the above reasons, outsourcing research appears to be focused on ITO (Dibbern et al. 2004), and the field of BPO somewhat neglected in comparison (Borman 2006) with little empirical work that examines BPO performance outcomes (Whitaker et al. 2006). Our research is an attempt to empirically study the drivers of BPO performance and address this gap in the literature.

Our study also confirms the important role that the IT organization plays in realizing strategic value from BPO relationships; we find that the greater the complexity and interdependencies of the outsourced process, the greater is the required level of technological investments in process execution and coordination. Thus, business leaders must ensure that the CIO is part of the BPO executive leadership, and that the IT organization staff is part of the ongoing team (Tornbohm 2006). As efficiency gains from BPO are driven more by process automation and sophisticated delivery models rather than by labor arbitrage (Singh et al. 2007), this linkage between IT and BPO will only become more pronounced.

Finally, the study contributes to the IPV. The latter was developed and tested in the context of intrafirm coordination. Consequently, interorganizational considerations of incentive conflict are absent from information processing approaches (Argyres 1999). Further, the ability to facilitate unstructured informal dialog through firm-specific communication codes is a key advantage of organizations relative to market-based contracting (Monteverde 1995). Thus, in interfirm settings, the means of communication advocated by information processing approaches must consider the added cognitive conflict between independent firms. In this study, we identify structural, process, and technological mechanisms that constitute IC of the BPO relationship and provide the incentives and means to process information in the relationship.

\section{A Model of BPO Performance}

Information requirements and information capabilities, the key constructs in our theoretical model of BPO performance, 


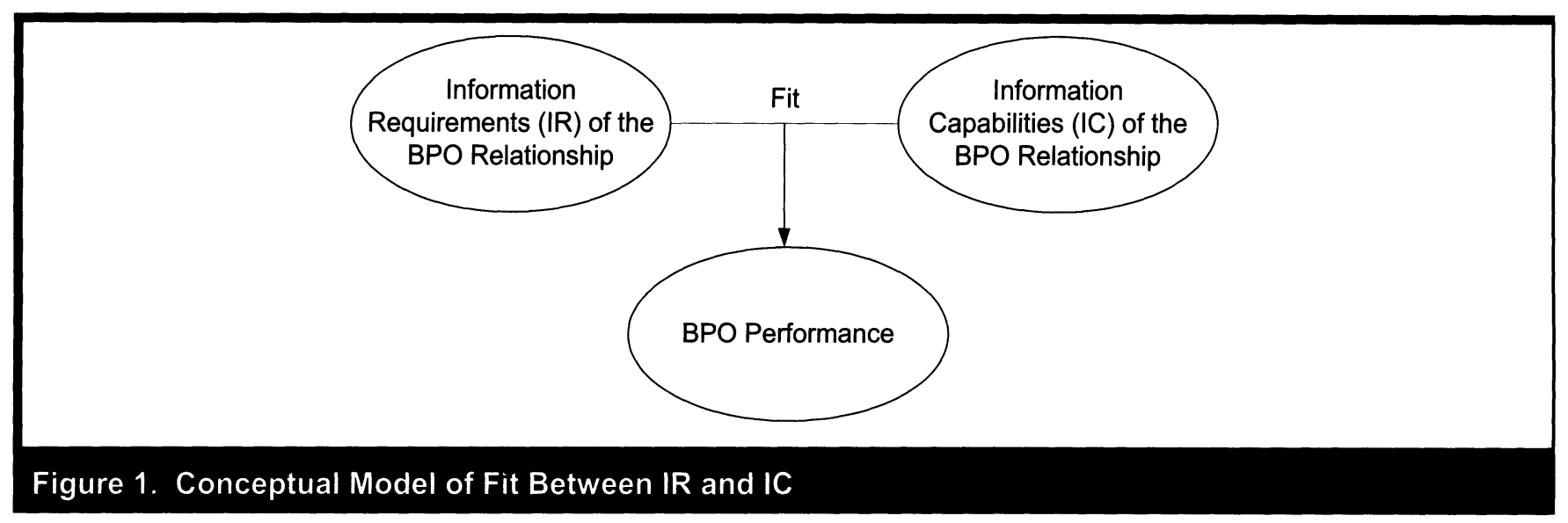

are derived from the IPV. We posit that satisfaction in BPO is determined by the fit between IC design and BPO task and relational environments that shape the IR of the BPO relationship. Our theoretical model of BPO performance is outlined in Figure 1.

\section{IR of the BPO Relationship}

Research in the information processing tradition largely defines the IR of a firm in terms of the volume of data about organizational activities that is gathered and interpreted by organization actors (Daft and Macintosh 1981) to address uncertainty in the task environment. Thus, we define the IR of the BPO relationship as the amount of information that must be collected, processed, and disseminated across firm boundaries to address uncertainty in the outsourced task environment. Task uncertainty, in turn, has its origin in two task attributes: complexity and interdependence (Daft and Lengel 1986; Galbraith 1973; Tushman and Nadler 1978).

Complexity of the outsourced process is defined in terms of low levels of analyzability and high levels of variety (Daft and Macintosh 1981; Withey et al. 1983). When a process is analyzable, outcomes are well understood, and process administrators follow an objective, computational procedure to resolve problems (Daft and Macintosh 1981; Daft and Weick 1984). Low levels of analyzability imply that it is relatively difficult to establish rules, procedures, and predetermined responses to potential problems during process execution and management. Fewer information cues require greater information processing to identify the type of information needed and the utility of that information for the outsourced process (Daft and Macintosh 1981).

Process variety is defined as the frequency of occurrence of process events that deviate from mean values of stability or uniformity of inputs/outputs, requiring different work processes than is the norm for completion of process objectives (Pentland 2003; Perrow 1967). High levels of process variety result in greater levels of process exceptions and deviations in the outsourced task environment and, hence, greater levels of information processing.

Likewise, the interdependence between the outsourced process and the user firm's value chain also increase the IR of the BPO relationship. The greater the interdependence, the more unexpected and frequent are forced adaptations in the BPO task environment (Daft and Lengel 1986). Further, the greater the interdependencies of the outsourced process, the greater is the number of process owners and the wider is the extent of impact assessment, bargaining, and reconciliation of disjunctive objectives among these owners (Hirschheim and Lacity 2000). Process interdependence also necessitates variety in coordination efforts required to transfer value back to the user firm. For these reasons, when the outsourced process is relatively modular and can be analyzed, modified, and enhanced, independent of other organizational processes, the BPO relationship is characterized by lower levels of IR. The relationships between process complexity, interdependence, and IR of the BPO relationship are illustrated in Figure 2.

Consistent with exploratory studies (Aron and Singh 2003; Aundhe 2003) and the above theoretical arguments, we suggest that it is useful to think of outsourced business processes along a continuum of IR, levels of which represent the amount of information that must be processed in the relationship to respond to complexity and interdependencies of the process. On one end, we have routine, modular business processes that are managed and executed relatively independent of information changes in the value chain. Next along the continuum are processes that involve rule-based processing of information changes in the task environment. 


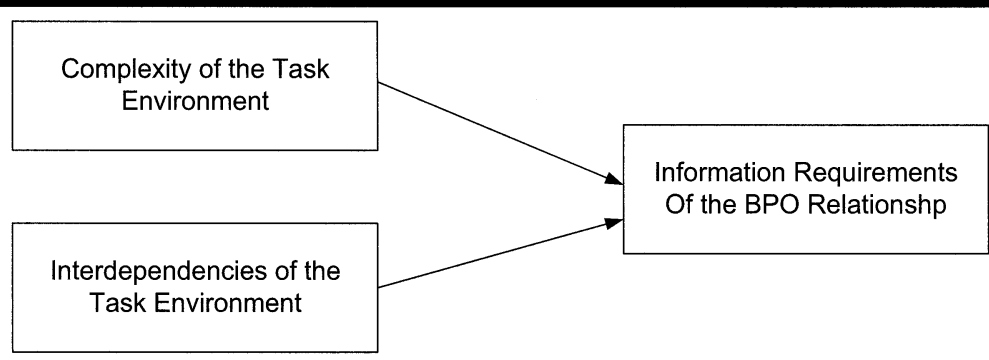

Figure 2. Process Complexity, Interdependence, and IR of the BPO Relationship

At yet another point along the continuum are processes that involve the design of information solutions and are less amenable to rule-based execution. These processes draw on and contribute critical information to the user firm's value chain and, in turn, require unstructured information intervention from the user firm. Finally, we have processes that are highly information intensive and involve significant, often real-time, information support from the user firm during their execution.

These different points on the continuum are illustrated in Figure 3 in the context of a credit card processing function. Functions like application form filling or other data entry are examples of modular information processing. In such cases, information exchange between the firms is often limited to batch transfer of process output. Tasks such as new credit card issuance access and record basic customer information, but the structured nature of the information allows much of the business logic to be implemented through rule-based information processing. On the other hand, unstructured informational functions like customer analytics involve access to multiple customer databases, the integration of these databases with data mining tools of the provider, and design of information solutions that link to multiple departments such as marketing and new product development. Expert information services such as the design or marketing of payment products are supported by information solutions such as customer analytics or financial analysis and, often, real-time information linkages to directly deliver critical business outcomes.

The relative complexity and interdependence of the above functions are mapped in Figure 4.

\section{IC of the BPO Relationship}

Each BPO relationship is embedded in a unique process context, and, therefore, differs in its IR. The information processing view of the BPO relationship suggests that observed variations in BPO forms represent strategies to increase participant firms' ability to reduce IR, or increase their capacity to adapt to their inability to reduce IR (Galbraith 1973). Given the exogenous nature of the outsourced process and IR, the IC design problem in BPO is that of creation of mechanisms through which the user firm and the provider can coordinate their behaviors and actions to address the IR of the BPO relationship and enhance performance.

Information processing theorists (Galbraith 1973; McCann and Galbraith 1981) find that the dominant strategies used by firms to increase their information capacity include greater hierarchy, creation of lateral relations, and investment in information systems. Organizational hierarchies make division of labor and interactions between interdependent actors in the firm more predictable. Lateral relations between organizational actors allow problems to be solved at the level they occur while organizational information systems allow for information processing without overloading the firm's normal communication channels.

However, these strategies do not account for incentive and cognitive conflicts that are unique to interfirm relationships (Argyres 1999; Gulati et al. 2005). Incentive conflict assumes potential for opportunism and arises from differing private benefits that accrue to independent firms wishing to exchange with each other. Incentive conflict between the user firm and the provider impacts their motivation to process required information accurately (Argyres 1999). Cognitive conflict assumes lack of availability of a common communication code for independent firms wishing to exchange with each other (Monteverde 1995) and arises due to the lack of a shared understanding of the decision rules inherent to the other firm and mutual interdependencies (Geanakoplos 1992; Gulati et al. 2005 ). Cognitive conflict between the user firm and the provider impacts their means to process information in a timely fashion. In developing IC of the interfirm BPO 

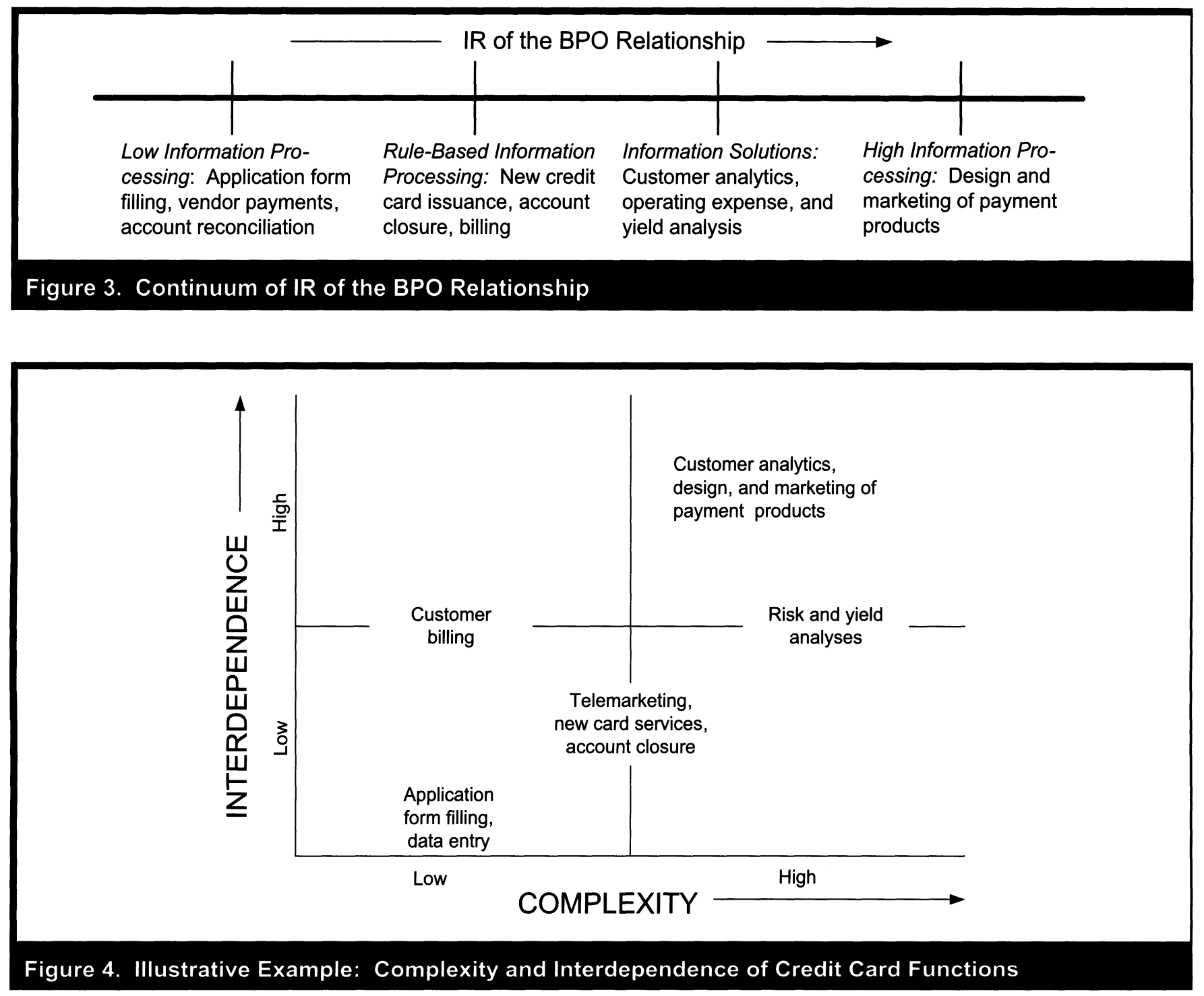

relationship, we define structures, processes, and technologies that, while providing the coordination benefits of greater hierarchy, lateral relations, and information systems, address incentive and cognitive conflicts in the BPO relationship.

Organizational hierarchy is substituted by the governance structure that formalizes the BPO relationship. In addition to sharing the coordination features of organizational hierarchies, the interfirm governance structure additionally aligns intent to share information and incentives to invest in allied processes and technologies. Similarly, relational processes perform the function of lateral relations while relational technologies provide the benefits of organizational information systems. Relational processes, in addition to enabling timely information sharing, help overcome diverse interpretations of changes in the information environment by the user firm and provider to develop shared understandings. Relational technologies comprise process technologies that enable timely incorporation of information changes in the execution of the process and coordination technologies that increase the amount and frequency of information exchange between firms to reduce information overload in the relationship. The joint impact of these three mutually reinforcing dimensions of IC has received little empirical attention. Each of these dimensions is described below.

\section{Governance Structure}

We define the BPO governance structure as the ownership and control structure used to formalize the relationship, and distinguish among these structures by the level of hierarchical 
control, length, and extent of formalization. Hierarchical elements in BPO governance include command structures and authority systems, incentive systems, control mechanisms, operating and change management procedures, private ordering mechanisms that bypass courts, and nonmarket pricing systems that enable accurate compensation for changes in task specifications (Stinchcombe 1985). Some of these elements such as incentive systems or pricing systems pertain to agency features of hierarchical control and address exchange hazards (Stinchcombe 1985). Yet others, such as command systems or operating procedures, pertain to coordination features that reduce the number of information signals that impinge on participant firms. A governance structure is hierarchical to the extent that the control and coordination elements it incorporates "replicate the control and coordination features associated with organizations, which are considered to be at the hierarchical end of the spectrum" (Gulati and Singh 1998, p. 781).

Greater hierarchical control is associated with greater IC of the BPO relationship. This is based on the ability of the agency features of hierarchy to reduce incentive failures through better monitoring and control by fiat (Williamson 1991), and the coordination features to reduce cognitive failures in networks of division of labor through formalization of roles, shared ownership, and greater systematization (Galbraith 1973; Gulati and Singh 1998). In this study, BPO governance structures in decreasing order of hierarchical control range from equity sharing structures such as joint ventures to arm's length contracts marked by competitive bidding that have few hierarchical controls built into them.

Consider two examples that illustrate the contrast in hierarchical control used to coordinate information between firms and emphasize that such structures are motivated by information processing concerns rather than by exchange hazards alone. The first example is that of an IT services firm in our sample that outsourced benefits management of its employees to reduce costs of process ownership, improve employee satisfaction, and focus on its core competencies. To meet these objectives, the service provider developed a web portal for the employees with enrollment, support, and self-service features. In addition, a 24 hour helpdesk service fielded employees' queries and educated them about different benefits. Since the provider's existing assets could easily scale to provide these process solutions, the user firm transferred ownership of the process to the provider through a fixed price arm's length contract.

The second example is that of a metals manufacturing firm in our sample that also outsourced its human resources function. Prior association between the firms, the presence of alter- native providers, and the potential of repeat business resulted in minimal appropriation concerns. However, the human resources process was characterized by a set of complex and unique information flows to deal with payroll calculations and retirement benefits for different categories of employees, which involved important information on exposure to specific hazardous materials. The labor agreements implicit in these calculations also needed to be frequently updated to reflect changing regulations and market conditions. Finally, the human resources system provided important inputs to pricing modules that generated the final price for quantities of different metals. Given the demanding IR of the task environment, the provider could not easily assume sole ownership of the process, prompting the manufacturer to take an equity stake in the provider.

In addition to the level of hierarchical control, we consider two related attributes - length and degree of formalizationin distinguishing among BPO governance structures. Fears of hold-up are alleviated in longer-term contracts (Vázquez 2007) to provide the incentive to undertake investments in other dimensions of high IC that address high IR. Further, long-term contracts do not need to be negotiated often and yield greater expectations of continuity. Thus, in longer-term contracts, firms are better predisposed to greater information sharing that characterizes high IC. Longer term contracts also provide more opportunity for mutual adjustments in behavior and learning (Anand and Khanna 2000) and improvement in how firms process IR of the relationship. These superior incentives and means to process information in longer-term BPO contracts are consistent with higher levels of hierarchical control in the relationship.

Finally, we posit that the extent of formalization in the BPO relationship or relative emphasis on control versus coordination also influences the IC of the governance structure. Greater levels of formalization lower the IC of the relationship through signaling a lack of trust (Ghoshal and Moran 1996) and shifting the focus and resources of the provider from information exchange aimed at problem solving to defending actions and choices (Sundaramurthy and Lewis 2003). Thus, we expect that longer-term BPO relationships with higher levels of hierarchical control and lower degree of formalization will be characterized by relatively greater IC.

\section{Relational Processes}

Relational processes in BPO enable timely sharing of information to schedule and synchronize outsourced tasks, clarify task outputs, and integrate outputs back into the user firm's value chain. Following prior research (Bensaou and Venkat- 
raman 1992), we characterize relational processes in the BPO relationship in terms of three dimensions: joint action, commitment, and conflict resolution. Along an increasing continuum, these dimensions represent greater relational embeddedness that affect the extent to which information is freely exchanged in the relationship.

Relational processes are especially important when the required task information is tacit and localized (Uzzi and Lancaster 2003; von Hippel 1994) or cannot be easily transferred through the contract. The user firm may have domain knowledge, while the service provider has expertise in executing and managing the outsourced process. These different information sets must be coordinated for efficient work design. Joint action, commitment, and collaborative conflict resolution complement adaptive limits of the contract to facilitate process execution. TiVo, a manufacturer of digital video recorders, outsourced customer support to rapidly develop distinctive capabilities. Success of the support function was contingent on helping customers install, understand, and use the product. TiVo worked closely with its provider to jointly develop processes and training materials that enabled customer agents to "think like a TiVo" customer (Linder 2004). The agents used the product in their own homes and mastered investigative problem solving techniques to provide superior customer solutions. In turn, the agents provided rich descriptions of customer problems back to TiVo's product development and marketing divisions. This example illustrates how relational processes enable timely information credentialing and access to strategic know-how to enhance IC of the BPO relationship.

As the rate of information change in the task environment increases, the information network between organizational actors must shift from being mechanistic or autonomous to being organismic or highly connected (Tushman and Nadler 1978). Thus, as IR of the BPO relationship increases, participant firms should promote tightly linked relational processes that increase the opportunity for feedback, synthesis of different points of view, and joint decision making that complement limits to adaptability of hierarchical governance structures.

\section{Relational Technologies}

The IPV posits that investments in IT increase the information capacity of the firm by reducing the information overload on the firm's communication channels (Galbraith 1973). Prior research on information processing (e.g., Zuboff 1988) suggests that two primary functions of organizational technologies are automating and informating. The former enables an increase in the amount of information processed per unit of time, while the latter facilitates proper routing of available information among organizational actors within the firm and between firms.

In the interfirm context of BPO, process technologies and coordination technologies provide benefits of automating and informating respectively. The use of IT in the outsourced process eliminates redundancies and adds efficiencies to process execution and management. Coordination systems increase connectivity between firms to facilitate a synergistic response to changes in the business environment. For instance, if a subscriber of a cable company changed her billing plan, coordination systems would communicate this change to the company that provided the customer support function so that billing questions may be answered seamlessly. Coordination systems also help monitor and manage the performance of the provider.

\section{Interrelationship Between Governance Structure, Relational Processes and Technologies}

Prior research (Poppo and Zenger 2002; Puranam and Gulati $2005)$ points to strong synergies between contractual and relational structures in outsourcing. Governance structures promote relational linkages by formally specifying a longterm commitment to exchange and promoting the expectation that firms will behave cooperatively. Moreover, the design of complex hierarchical controls requires participant firms to mutually determine and commit to processes for dealing with potential contingencies, thereby influencing the development of social relations.

Similarly, the development and sustenance of relational processes enables the refinement of hierarchical controls to reflect participant firms' behavior and learning. Further, hierarchical governance structures limit the flexibility of firms to respond and adjust to unforeseen contingencies (Argyres and Liebeskind 1999) and do not guarantee a bilateral resolution of such contingencies. In this case, relational processes complement the adaptive limits of governance structures to foster bilateralism and mutual adjustments in behavior required for adaptation.

The improved information processing that IT affords is also synergistic with hierarchical governance structures and tight relational processes. A firm's technological resources enhance and create channels of communication, introduce new decision mechanisms, and enable more efficient use of information during task execution (Galbraith 1973). All of these capabilities enable complex planning and coordination that is inherent to hierarchical governance structures and tight 
relational processes. Hierarchical governance structures involve a significantly greater number of embedded rules and routines; IT commits these rules to memory, thereby increasing the viability of these structures (Monteverde 1995). IT also supports tight relational processes by reducing information overload associated with extensive ongoing collaboration and providing a communication channel that allows the user firm and the provider to be continuously informed about each other's process decisions and actions (Argyres 1999).

Given the synergy among these three dimensions of IC, we use an integrated representation of IC comprising the governance structure, relational processes, and information technologies in the BPO relationship. The second-order construct of IC is depicted in Figure 5.

\section{The Conceptualization of Fit}

\section{Fit as a Theoretical Match Between IR and IC}

The IPV posits that organizations will be more effective when there is a match between their information processing requirements and information processing capacity of the organization's structure (Tushman and Nadler 1978). Thus, we posit that the IC of the BPO relationship must "fit" the IR of the relationship to maximize performance, and that over- or underinvestment in IC lowers performance. Venkatraman (1989) identifies six different types of fit-moderation, mediation, matching, gestalts, profile deviation and covariation-each with a distinct theoretical implication and requiring the use of specific analytical methods. We conceptualize fit as a theoretically defined "match" (Venkatraman 1989) between levels of IR and IC; we posit that in order to be effective, BPO relationships, which differ in their IR, must be governed by aligned IC, reflected in the choice of structural, process, and technological mechanisms in the relationship. Patterns of fit and misfit between IR and IC are shown in Figure 6.

We draw on the IPV to posit that if the organization does not consciously match IR and IC, reduced performance standards will automatically ensue in configurations of misfit (Tushman and Nadler 1978). For example, in configuration $C_{4}$ in Figure 6, IC of the BPO relationship are inadequate to deal with uncertainty in the outsourced task environment; a less than optimal amount of information renders decision making ineffective. Thus, the relationship lacks critical coordination capabilities required to create value in the outsourced task environment and transfer it to the user firm. On the other hand, the IC in configuration $\mathrm{C}_{1}$ is in excess of IR. Excessive hierarchy and redundancy of organizational resources render management of the BPO relationship relatively inefficient. Further, managerial time and effort involved in creation of high IC are costly and engender performance expectations that are unmet, not only because of misaligned IC but also because of the limits to value creation inherent to transactional BPO. These costs and management expectations may explain why IC misfit has a significant negative impact on perceived performance gains in transactional $\mathrm{BPO}$ initiatives. Consequently, performance of configurations $\mathrm{C}_{2}$ and $\mathrm{C}_{3}$, where IC fit the IR of the relationship, is relatively higher than that of cells $C_{1}$ and $C_{4}$, where there is a misfit. Thus, we hypothesize:

\section{Hypothesis 1: The performance of $B P O$ relation- ships that achieve a fit between IR and IC will be higher than that of incongruent relationships whose $I C$ do not fit their IR.}

\section{Configurations of Fit: Transactional and Transformational BPO}

IR may be minimal or extensive, as shown in Figure 6, reflecting two dominant classes of BPO initiatives that we characterize as transactional $B P O$ and transformational $B P O$ respectively (Linder 2004). Given that IR of the relationship is determined by outsourced process complexity and interdependence, transactional and transformational BPO are characterized by variance in complexity and interdependence of the outsourced process.

Low IR of transactional BPO exchanges reflect high levels of process analyzability and low levels of process variety and interdependence. These process attributes enable a relatively complete specification of contingent obligations and establishment of property rights in an arm's length contract with little hierarchical control (Baker 1990; Lee et al. 2004; Uzzi 1997). Such a contract generates relational rents by lowering transaction costs (Dyer and Singh 1998), is short-term, and involves greater levels of formalization. Ease in process transferability and ownership also renders the BPO relationship mechanistic with a lower need for rich information exchange processes or technologies. Thus, modular or limited information processing in transactional BPO relationships requires low levels of matching IC or structural, process and technological mechanisms, to coordinate activities between participant firms.

For instance, consider search engine AltaVista's outsourcing of e-mail customer support (Linder et al. 2002). The outsourced process was simple and involved limited interdepen- 

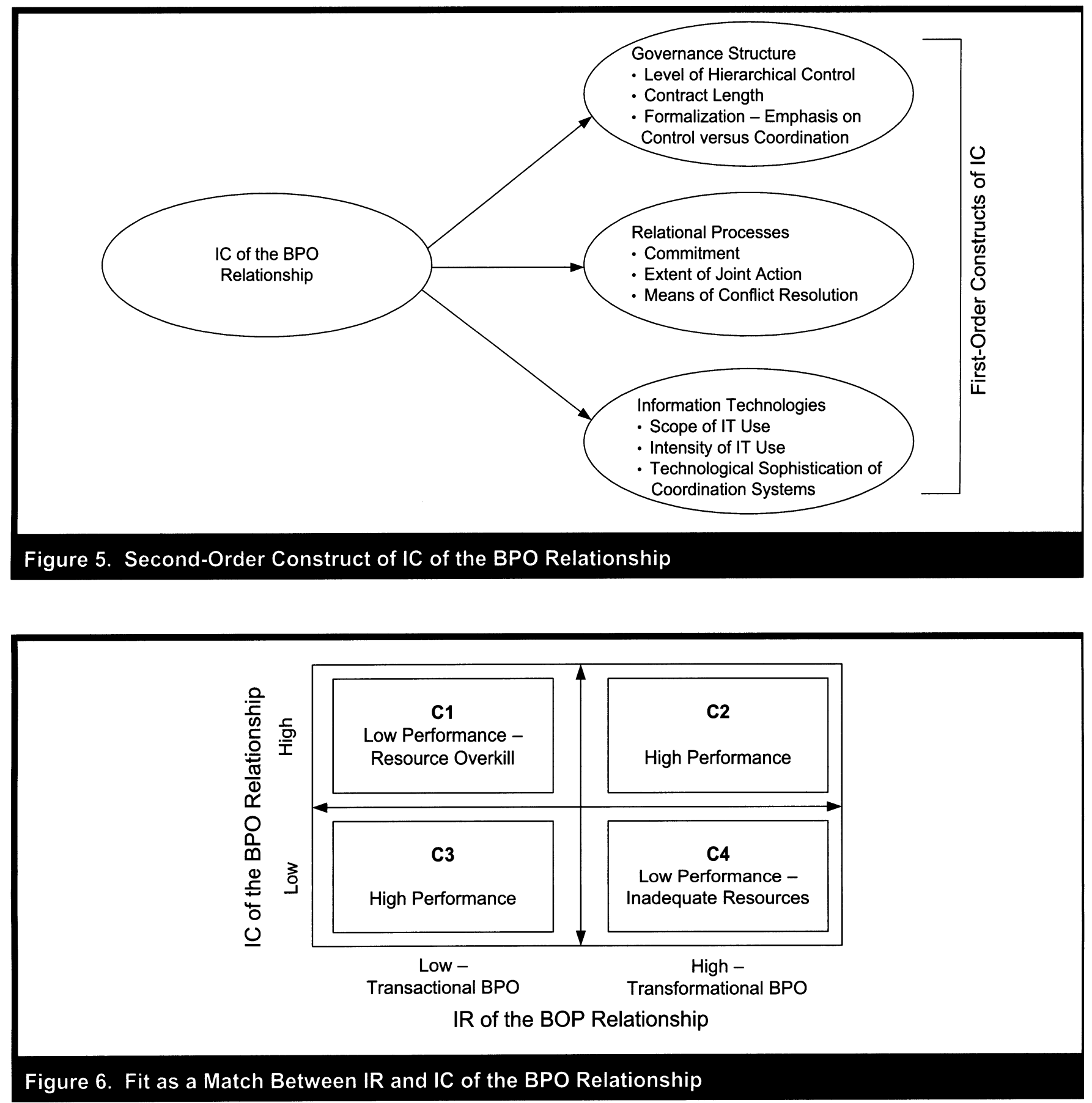

dencies with the user firm's value chain. Thus, the matching IC involved minimal interaction with the provider to manage the relationship, with responsibilities, service levels, and pricing structures clearly spelled out in an arm's length contract. Further, the relationship comprised limited investment in technological capabilities. AltaVista was able to disseminate training materials, monitor service, and negotiate new pricing structures via the web and telephone. This fit between
IR and IC reduced the cost of the support division by nearly 40 percent (Linder et al. 2002).

On the other hand, the high IR of transformational BPO initiatives reflects high levels of process complexity and interdependence. Prior research (Anand and Khanna 2000) finds that in these initiatives, it is easier to monitor activities of partners through more hierarchical contracts than via arm's 
length contracts. Such contracts generate relational rents by providing incentives for value creation (Dyer and Singh 1998), are long-term, and emphasize coordination over control. Information processing in relationships is also enabled by tight relational linkages and sophisticated coordination technologies. This is similar to partnership-like arrangements described in the IT outsourcing literature (Kern 1997). The user firm and provider are committed to creating value and engage in high levels of joint action, information exchange, and knowledge transfer (Baker 1990; Ring and Van de Ven 1992). Thus, high levels of information processing in transformational BPO relationships require high levels of matching IC or structural, process, and technological mechanisms, to coordinate activities between participant firms.

Transformational BPO relationships are especially pertinent to recent moves by CIOs toward consolidating back office functions into shared services units. For instance, Procter \& Gamble has consolidated all of its back office functions into its Global Business Services unit. This integration of services allows for their management by work process rather than by function to leverage scale and synergies across departments. For example, the purchase-to-payment for suppliers, which was fragmented across procurement, accounting, and finance, is now handled by one group of people to avoid handovers across multiple functions. One part of the process, accounts payable, is outsourced, while procurement and finance remain in-house. In such cases, the outsourced task is complex and shares tight interdependencies with the user firm's value chain, resulting in high IR. As a consequence, the process workers in the user firm and the provider share a tight relationship and manage this process together as one team for seamless process delivery. Procter \& Gamble's CIO summed up the transformational nature of such BPO relationships in the shared services unit in a recent interview:

It was not a case of flat-out outsourcing...P\&G was offering unique capabilities-skills, knowledge, work processes, and technologies-to each of its outsourcing partners, which enabled them to create new business opportunities (Bloch and Lempres 2008).

These differences between transformational and transactional BPO are summarized in terms of process attributes, IR, aligned IC and impact in Table 1.

\section{Comparative Analysis of BPO Performance Across Configurations of Fit}

In this section, we examine performance differences between transactional and transformational BPO. The outsourced process in transactional BPO is modular with limited reach while that in transformational BPO shares greater interdependencies in the user firm's value chain. Thus, the output of transformational BPO initiatives has a more pervasive impact, often forming critical input to other processes. Such firm-wide integration of process output in transformational BPO directly impacts competitiveness through creation of enterprise-level competences.

This difference between the impact of transactional and transformational BPO may also be understood in terms of the difference in development of two key competences of firms: component competence (the expertise in localized activities) and architectural competence (the ability of a firm to integrate competencies to develop new ones) (Henderson and Cockburn 1994). Transformational BPO, through coordinated execution of the outsourced process and deployment of process output across the organization, likely facilitates development of architectural competences. However, the main function of IC in transactional BPO is to transfer localized process expertise and contextual knowledge to the provider, who manages the process relatively independently. This likely develops component competences in the user firm. Prior research (Henderson and Cockburn 1994) finds that architectural competencies that facilitate development of new competences explain significant variance in productivity across firms, suggesting that transformational BPO has a greater impact on the user firm's competitiveness.

This greater reach and impact of transformational BPO initiatives relative to transactional BPO suggests that IC misfit will be more detrimental in such initiatives. The user firm is not only divested of key architectural competences that impact its competitiveness but also, given the greater pervasiveness of the outsourced process, incurs significantly higher costs in terms of organizational disruption relative to transactional BPO. Thus, we posit

\section{Hypothesis 2: The negative impact of misfit on exchange performance is relatively higher in the case of transformational BPO arrangements (marked by high IR) than in the case of transactional $B P O$ arrangements (marked by low IR).}

\section{Empirical Analysis}

\section{Data Collection}

The data for this study were obtained through a survey of senior executives responsible for the management and review 
Table 1. Comparison of Transactional and Transformational BPO Initiatives

\begin{tabular}{|c|c|c|}
\hline & Transactional BPO & Transformational BPO \\
\hline Process Attributes & $\begin{array}{l}\text { High analyzability } \\
\text { Low variety } \\
\text { Low interdependence }\end{array}$ & $\begin{array}{l}\text { Low analyzability } \\
\text { High variety } \\
\text { High interdependence }\end{array}$ \\
\hline IR & Low & High \\
\hline Aligned IC & $\begin{array}{l}\text { - Low levels of hierarchical control } \\
\text { - Mechanistic relational structure with low } \\
\text { levels of joint action, commitment, and } \\
\text { conflictual conflict resolution } \\
\text { - Low technological capabilities }\end{array}$ & $\begin{array}{l}\text { - High levels of hierarchical control } \\
\text { - Organismic relational structure with high } \\
\text { levels of joint action, commitment, and } \\
\text { collaborative conflict resolution } \\
\text { - High technological capabilities }\end{array}$ \\
\hline Impact & $\begin{array}{l}\text { Increase operational efficiency; largely pro- } \\
\text { cess level outcomes, e.g., reduce process } \\
\text { costs }\end{array}$ & $\begin{array}{l}\text { Enhance firm competitiveness; largely } \\
\text { enterprise level outcomes; e.g., increase } \\
\text { revenue, innovation }\end{array}$ \\
\hline
\end{tabular}

of outsourced business processes. Based on comprehensive reviews of the literature and initial interviews with $20 \mathrm{BPO}$ experts, ${ }^{5}$ we developed a structured questionnaire that was pretested with a total of 30 medium to large firms, market research firms, and academicians. The instrument was tested for clarity of content, scope, and purpose (or content validity). A seven point Likert scale was used for most questions; however, some questions involved binary choices.

The desired sample included small to large organizations across diverse industries that had outsourced one or more business process. Our target list drew on active compilations of outsourcing firms, industry association referrals, and outsourcing advisory referrals. Related research on ITO, in surveying executives, defines populations and response rates based on those who will pre-commit to respond (Poppo and Zenger 2002). The normative response rates based on precommitted samples are as high as 40 percent (Anderson and Narus 1990). A total of 600 pre-committed surveys were mailed, with follow-up letters five weeks later. We received a total of 145 valid responses of which 127 were complete in all respects. This response rate of approximately 24 percent was slightly lower than expected, and was likely due to the lengthy and extensive nature of the questionnaire. However, it is consistent with rates in similar surveys in the literature (Pavlou et al. 2007; Poppo and Zenger 2002). The final sample was representative of a range of outsourcing objectives for which there was sufficient variance in task attributes.

\footnotetext{
${ }^{5}$ The subject experts comprised directors of strategic outsourcing practices in Fortune 100 firms (in financial services, healthcare, retail, and high-tech), outsourcing advisory consultants, leading service providers, and academicians.
}

All respondents were assured that their responses would remain confidential and that results would be reported only in aggregate, thereby addressing privacy concerns and minimizing potential bias in self-reported data. To test for potential response bias, we compared the firm size in the sample to the larger population. The sample and population did not appear to differ in terms of firm size. We also compared questionnaires turned in early with questionnaires turned in later along a number of variables-firm size, industry, respondent position, exchange attributes and service satisfaction - to check for nonresponse bias (Armstrong and Overton 1970; Poppo and Zenger 2002). No significant differences were found between early and late respondents. We also checked for the presence of common method bias (Podsakoff et al. 2003) and concluded that common method bias did not likely impact survey responses.

Finally, a section of the raw data was also randomly subjected to independent cross validation exercises. For a random sample of 25 firms, we requested the respondent firm to identify the vendor for the outsourced process for the purpose of a brief interview. Ten firms obliged, and we interviewed the vendors for the outsourced process to obtain relevant process information. The two information sets in the user firm-provider dyad were mutually consistent.

\section{Measures}

\section{Exchange Performance}

Our use of service satisfaction as a key performance metric is consistent with prior measures of outsourcing performance found in the information systems literature (e.g., Grover et al. 
1996; Marcolin and McLellan 1998). Satisfaction is a proxy for perceived effectiveness in working partnerships like BPO (Barber and Venkatraman 1986; Poppo and Zenger 2002). It is also a significant determinant of future actions, including repeat business, positive word-of-mouth, and loyalty (Barber and Venkatraman 1986). Its use as a performance metric is also supported by the argument that high levels of satisfaction represent realized performance expectations (Dibbern et al. 2004). However, since performance goals often relate to the overall cost and quality of service, prior research (Lee and Kim 1999; Poppo and Zenger 2002) has largely emphasized satisfaction with service quality, where measures of the latter are based on the SERVQUAL instrument (Parasuraman et al. 1985).

In this study, we measure the user firm's level of satisfaction with four dimensions of service: reliability, responsiveness, systematization, and innovation (Sureshchandar et al. 2002). Reliability refers to the ability to perform contracted services dependably and accurately. Responsiveness reflects willingness to help customers and provide prompt service. Systematization refers to the processes, procedures, systems, and technology that make a service a seamless one. Innovation refers to the ability to leverage process knowledge to deliver a range of process enhancements that go beyond performance expectations of the user firm and contracted service level agreements. Measures of these four dimensions are adapted from Sureshchandar et al. (2002). Our measure of innovation is also consistent with the literature on service innovation and delight (Hipp and Grupp 2005; Oliver et al. 1997). The use of these four dimensions of satisfaction is consistent with recent research, which finds that there is a need to study performance outcomes in BPO beyond the traditional outcomes of quality and cost (Whitaker et al. 2006). We measure satisfaction on a seven-point scale where "1" represents highly dissatisfied and "7" represents highly satisfied.

\section{Explanatory Variables}

IC is developed as a second order construct with governance structure, relational processes, and information technologies as first order constructs. Factor scores for the integrative latent representation of IC were used in subsequent analyses. Measures of the three dimensions of IC are adapted from prior research. The governance structure is identified by the degree of hierarchical control (Gulati and Singh 1998), the length of the relationship, and the degree of formalization or relational emphasis on control versus coordination (Bensaou and Venkatraman 1995; Gulati and Singh 1998; Tushman and
Nadler 1978). Relational processes are identified by the levels of commitment (Gardner and Cooper 1988), extent of joint action (Bensaou and Venkatraman 1995; Heide and John 1990), and (collaborative versus adversarial) conflict resolution (Linder 2004; Bensaou and Venkatraman 1995). The extent of use of relational technologies is measured by the scope and intensity of use of IT in the outsourced process, and sophistication of coordination systems (Bensaou and Venkatraman 1995).

In order to perform a comparative analysis of performance across the two identified categories of BPO relationships, we define the variable IC to be equal to one for cases where a firm employs high levels of IC, and equal to zero for cases where a firm uses low levels of IC. Following prior research, we use the median value as the threshold for high IC. To estimate whether IR of the BPO relationship determines its IC, we use the following probit model to estimate the choice of IC for a given BPO relationship:

$$
\operatorname{Pr}\left(Y_{i}=1\right)=\Phi\left(\beta^{\prime} X_{i}\right)
$$

Here, $Y_{i}$ represents the capabilities choice (high or low) for BPO relationship $i, X_{i}$ is a vector of determinants of governance choice, including IR and other control variables, $\beta$ is the vector of coefficients of these determinants and $\Phi($.$) is the$ standard normal CDF.

To measure IR, we draw upon on Keller's (1994) measurement of information processing by project groups. Two items measure the amount of information communicated within the user firm and with the service provider. Two other items ask about the use of external agencies such as law firms, consulting firms, etc., and the different stages of the outsourcing process in which these agencies were used (for example, contract negotiation, vendor evaluation, etc.). The observed IR was regressed on process complexity and interdependence to obtain predicted values of IR. We use comparison tests to determine the threshold value for classification of IR as high or low. We find that IR does distinguish between high and low IC, and that the value of 0.693 for IR corresponds with the highest average of the sensitivity of 67.8 and specificity of 90.2 .

We argue that BPO performance is contingent on the degree to which the IC of the BPO relationship are aligned with the IR of the BPO relationship. To test this proposition, we develop a measure of IC misfit which captures the probability that too high a level of IC are employed for transactions with high IC and too low a level of IC are employed for transactions with low IC. Consistent with prior research (Leiblein 
et al. 2002), we estimate IC misfit as the absolute difference between the observed and predicted values of IC from the probit estimation.

\section{Control Variables}

Our performance models for both high and low IC also include a series of controls for firm size, firm tenure, mutual trust, environmental dynamism, outsourcing experience, and industry effects. Mutual trust and environmental dynamism control for uncertainty in the BPO relationship and allied exchange hazards posited in the institutional economics literature. All measures of controls are adapted from prior literature. We measure firm size as the firm's average domestic sales during the period 2000-2003. Firm tenure is measured by the number of years elapsed since the firm's founding, mutual trust is measured by whether the user firm and service provider had a history of prior cooperative association, and environmental dynamism is measured by the rate of change in product/service technologies, innovations, and customers' demands/buying habits in the user firm's industry. The firm's experience in managing outsourcing relationships is measured by the number of active outsourcing relationships in the firm other than the focal BPO initiative. We controlled for industry differences with two dummy variables that represent the primary SIC code of the user firm: wholesale and retail trade and finance, insurance and real estate; manufacturing was used as the default or benchmark sector.

\section{Data Analysis}

Our empirical analysis proceeds in several stages. First, we regress observed IR on process complexity and interdependence to obtain predicted values of IR that we use in the analyses.

$$
I R_{i}=\alpha \text { Complexity }_{i}+\beta \text { Interdependence } e_{i}+\varepsilon_{i}
$$

We use a structural model to validate a latent representation of IC and obtain factor scores.

$$
\begin{aligned}
& \text { IC }_{i}=\alpha \text { Contract_Type }_{i}+\beta \text { Contract_Length }_{i}+ \\
& \gamma \text { Formalization }_{i}+\delta \text { Joint Action }_{i}+\zeta \text { Commitment }_{i}+ \\
& \eta \text { Metrics }_{i}+\kappa I T \text { Scope }_{i}+\lambda \text { IT Intensity }_{i}+\mu \text { Coordn }_{1} \\
& \text { Systems }_{i}+\mu_{i}
\end{aligned}
$$

All constructs are tested for convergent and discriminant validity. We test the former by checking the critical ratios of each factor and the latter by comparing construct variance extracted with squared correlations among constructs (Segars and Grover 1998).

The next stage involves a test of the performance impact of fit between IR and IC. Binary transformations of both variables are used in the analyses. Preliminary evidence of the impact of misfit (Hypothesis 1) is provided by t-tests of difference in performance between low and high IR for a given level of investment in IC. We test whether Satisfaction $(I C=1$, $I R=1)-$ Satisfaction $(I C=1, I R=0)$ and Satisfaction $(I C=0$, $I R=0)$ - Satisfaction $(I C=0, I R=1)$ is positive and significant. The t-tests also provide preliminary evidence of whether misfit has a more pronounced impact on transformational $\mathrm{BPO}$ relative to transactional BPO (Hypothesis 2). We test whether Satisfaction $(I C=0, I R=1)$ - Satisfaction $(I C=1, I R=0)$ is negative and significant.

Venkatraman (1989) suggests that in order to test fit as a theoretical match between two variables, the residuals from the regression of one variable (in this case, IC) on the other (in this case, IR) must be related to the criterion variable (in this case, satisfaction). Thus, in order to estimate the performance impact of fit between IR and IC, we first estimate a first stage probit selection model of IC choice as a function of IR of the BPO relationship.

$$
\operatorname{Pr}\left(Y_{i}=1\right)=\Phi\left(\beta^{\prime} X_{i}\right)+\delta_{i}
$$

IC misfit, which is the absolute value of the residual ${ }^{6}$ from this first stage model, is incorporated in second stage OLS regressions of satisfaction. Incorporating this measure for high (low) IC provides a test of performance of firms that invested in high (low) IC but had good reason to invest in low (high) IC, that is, it provides a test of overinvestment (underinvestment) in IC.

Our two stage regression model also enhances the validity of the residual analysis by correcting for endogeneity of IC choice. Firms self-select the observed IC based on their own analyses of performance outcomes. The failure to correct for unobserved firm and transactional factors that simultaneously influence IC choice and performance produces biased, inconsistent estimates (Heckman 1979; Leiblein et al. 2002). To account for possibly endogenous IC choices, we construct the inverse Mills ratio, $\lambda_{j i}$ using the predicted probabilities from the probit model.

\footnotetext{
${ }^{6}$ An alternative way of measuring misfit would be to use the absolute difference between IC and IR as a measure of misfit. Although this measure has intuitive appeal, prior research (e.g., Venkatraman 1989) recognizes important problems pertaining to the use of difference scores, primarily the possibility of spurious association with an external variable and spurious relation to the performance variable through the effects of its components.
} 


$$
\begin{aligned}
\lambda_{1 i}= & \varphi\left(\beta^{\prime} X_{i}\right) /\left(\Phi\left(\beta^{\prime} X_{i}\right)\right) \text { for transactions with high IC (i.e., } \\
& \mathrm{j}=1) \\
\lambda_{0 i}= & -\varphi\left(\beta^{\prime} X_{i}\right) /\left(\left[1-\Phi\left(\beta^{\prime} X_{i}\right)\right]\right) \text { for transactions with low IC } \\
& (\text { i.e., } \mathrm{j}=0)
\end{aligned}
$$

This ratio is then included as a control in the second-stage performance models. Second-stage models, which incorporate the self-selection correction, provide consistent, unbiased estimates.

$$
\begin{gathered}
\text { Satisfaction }_{j i}=\alpha_{j} \text { IC Misif }_{j i}+\beta_{j} \text { Controls }_{j i}+\gamma_{j} \lambda_{j i}+\omega_{j i} \\
(j=0,1)
\end{gathered}
$$

The errors $\omega_{0 i}$ and $\omega_{1 i}$ are assumed to be distributed normally and independently, with mean zero and constant variance. $\gamma_{0}$ and $\gamma_{1}$ capture the correlation of the "unobservables" of the selection equation (1) with the "unobservables" of the performance equations $j=0$ and $j=1$ respectively; thus, a test of whether $\gamma_{0}$ and $\gamma_{1}$ are statistically different from zero measures the endogeneity of IC selection. In both stages, we use zscores for all variables to account for measurement differences. A negative and significant coefficient for $I C$ misfit provides support for Hypothesis 1. A positive and significant difference between the coefficient of IC misfit for low IC $(\mathrm{j}=0)$ and that for high IC $(\mathrm{j}=1)$ provides support for Hypothesis 2.

\section{Results}

\section{IR of the BPO Relationship}

The adjusted $\mathrm{R}^{2}$ for the regression of observed IR on complexity and interdependence of the outsourced process is 0.40 . Regression weights for both variables are significant at the 1 percent level. The correlation between predicted and observed IR is nearly 0.66 , indicating good fit. Further, all results reported below are robust to the use of both observed and predicted IR.

\section{IC of the BPO Relationship}

Correlations among the three first-order dimensions of IC are significant but below the limit of 0.90 (Bagozzi et al. 1991). Hence, a second-order factor model comprising an integrative latent representation of IC is useful in explaining such correlations (Segars and Grover 1998). Table 2 presents the factor loadings for the second-order IC construct, while Table 3 provides the factor loadings for the first-order dimensions of IC. All loadings are significant and of high magnitude.
We find a significant positive correlation between IR and IC. The Spearman correlation coefficient of 0.58 is significant at the 1 percent level, providing preliminary evidence of fit.

\section{Performance Impact of Misfit: T-tests of Performance Differences}

Table 4 presents the results of t-tests of performance differences between low IR (IR = 0 and high IR $(I R=1)$ for both choices of IC. We find that investment in low (high) IC when IR is high (low) has a significant, negative impact on performance, providing preliminary support for Hypothesis 1 . The magnitude of such impact is higher for low IC for nearly all dimensions of satisfaction, implying that the negative performance impact of underinvestment is higher than that of overinvestment. This result provides preliminary support for Hypothesis 2.

\section{Switching Regression Estimates: First-Stage Governance Choice Estimates}

Table 5 presents the results from two potential governance choice models. Model I presents a baseline case comprising controls, while Model II introduces IR as an explanatory variable. The results for the controls are largely aligned with expectations and results published in the literature. The significantly positive coefficient of firm size is consistent with research findings (Leiblein et al. 2002) that larger firms often have the superior financial and human resource endowments required to invest in high IC. The significant positive coefficient of environmental uncertainty is also consistent with the findings of prior research, which suggests that continual adaptation to business disturbances requires extensive coordination, necessitating investment in high levels of IC. The coefficients for outsourcing experience and prior association, although significant in Model I, turn insignificant in the final model, suggesting that rather than having an independent effect, these variables picks up some of the effect of IR on IC choice. This also suggests that prior association, in addition to fostering trust and cooperation between participant firms, aids coordination by helping specify the interface between them better.

The positive, significant coefficient of IR in Model II emphasizes its importance in influencing sample firms' choice of IC. Given the results of the $\log$ likelihood ratio tests and the pseudo- $\mathrm{R}$ square estimates presented at the bottom of Table 5, the estimates from Model II are used to formulate the inverse Mills ratio for the second-stage performance models. 


\begin{tabular}{|l|l|c|c|c|}
\hline \multicolumn{2}{|c|}{ Table 2. Estimates for the Second-Order IC Construct } & \multicolumn{2}{c|}{$\begin{array}{c}\text { Composite } \\
\text { Reliability }\end{array}$} & $\begin{array}{c}\text { Variance } \\
\text { Extracted }\end{array}$ \\
\hline \multirow{2}{*}{ Construct } & \multicolumn{1}{|c|}{ Indicators } & $\begin{array}{c}\text { Standard } \\
\text { Loading }\end{array}$ & 0.75 & 0.50 \\
& GC & 0.64 & & \\
\cline { 2 - 4 } & Relational Processes & 0.60 & & \\
\cline { 2 - 4 } & Information Technologies & 0.86 & & \\
\end{tabular}

All loadings were significant at $p<0.01$

\section{Table 3. Estimates for the First-Order IC Subcontructs}

\begin{tabular}{|c|c|c|c|c|c|}
\hline $\begin{array}{c}\text { Second-Order } \\
\text { Construct }\end{array}$ & $\begin{array}{l}\text { First-Order } \\
\text { Construct }\end{array}$ & Indicators & $\begin{array}{l}\text { Standard } \\
\text { Loading }\end{array}$ & $\begin{array}{l}\text { Composite } \\
\text { Reliability }\end{array}$ & $\begin{array}{l}\text { Variance } \\
\text { Extracted }\end{array}$ \\
\hline \multirow[t]{9}{*}{ IC } & \multirow[t]{3}{*}{ Governance Structure } & Hierarchical Control & 0.88 & \multirow[t]{3}{*}{0.82} & \multirow[t]{3}{*}{0.60} \\
\hline & & Contract Length & 0.80 & & \\
\hline & & Degree of Formalization & -0.63 & & \\
\hline & \multirow[t]{3}{*}{ Relational Processes } & Joint Action & 0.79 & \multirow[t]{3}{*}{0.85} & \multirow[t]{3}{*}{0.59} \\
\hline & & Commitment & 0.78 & & \\
\hline & & Conflict Resolution & 0.71 & & \\
\hline & \multirow[t]{3}{*}{ Information Technologies } & Scope of IT Use & 0.78 & \multirow[t]{3}{*}{0.79} & \multirow[t]{3}{*}{0.56} \\
\hline & & Intensity of IT Use & 0.72 & & \\
\hline & & Coordination Infrastructure & 0.73 & & \\
\hline
\end{tabular}

All loadings were significant at $p<0.01$

\section{Table 4. T-tests for Difference in Performance}

\begin{tabular}{|c|c|c|c|c|c|c|}
\hline & \multicolumn{3}{|c|}{ High IC } & \multicolumn{3}{|c|}{ Low IC } \\
\hline & $\begin{array}{l}\text { High IR } \\
\text { (a) }\end{array}$ & $\begin{array}{c}\text { Low IR } \\
\text { (b) }\end{array}$ & $\begin{array}{c}\text { Diff } \\
(b-a)\end{array}$ & $\begin{array}{l}\text { High IR } \\
\text { (c) }\end{array}$ & $\begin{array}{c}\text { Low IR } \\
\text { (d) }\end{array}$ & $\begin{array}{c}\text { Diff } \\
\text { (c-d) }\end{array}$ \\
\hline Reliability & 5.44 & 4.41 & $-1.03^{\star \star \star}$ & 3.26 & 4.85 & $-1.59^{\star \star \star}$ \\
\hline Responsiveness & 5.82 & 4.78 & $-1.04^{\star \star \star}$ & 3.79 & 4.85 & $-1.06^{\star \star}$ \\
\hline Systematization & 5.76 & 4.71 & $-1.05^{\star \star \star}$ & 4.00 & 4.75 & -0.75 \\
\hline Innovation & 5.58 & 4.55 & $-1.03^{\star \star \star}$ & 3.31 & 4.76 & $-1.45^{\star \star \star}$ \\
\hline
\end{tabular}

${ }^{\star \star} p<0.05 ;{ }^{\star \star \star} p<0.01$

\section{Table 5. Probit Estimates for First-Stage IC Choice Model ${ }^{\dagger}$}

\begin{tabular}{|l|c|c|}
\hline \multicolumn{1}{|c|}{ Independent Variables } & Model I & Model II \\
\hline Intercept & $0.630^{\star \star \star}$ & $0.728^{\star \star \star}$ \\
\hline Firm Size & $0.618^{\star \star \star}$ & $0.534^{\star \star \star}$ \\
\hline Firm Tenure & 0.185 & 0.139 \\
\hline Prior Association & $0.248^{*}$ & 0.075 \\
\hline Environmental Uncertainty & $0.482^{\star \star \star}$ & $0.375^{\star \star}$ \\
\hline Outsourcing Experience & $0.345^{\star *}$ & 0.131 \\
\hline IR & & $0.713^{\star \star \star}$ \\
\hline N & 127 & 127 \\
\hline Log Likelihood & -60.75 & -50.76 \\
\hline Pseudo-R & 0.22 & 0.39 \\
\hline
\end{tabular}

${ }^{\dagger}$ Positive coefficients indicate a greater probability of choice of high IC.

${ }^{* \star} p<0.05 ;{ }^{* \star *} p<0.01$ 


\section{Second-Stage Performance Models}

Tables 6 through 9 provide the results of our performance models - satisfaction with service reliability, responsiveness, systematization, and innovation respectively. In each table, Model I provides a baseline specification that includes controls and IC alone. A comparison with Model II, which adds the correction for self-selection and IC misfit, illustrates the impact of these two variables on performance. While Model II assumes the impact of the controls and self-selection to be equivalent across both low and high IC, Model III separately estimates models for the two IC choices while correcting for self-selection. F-tests for all models across the four measures of performance reject the hypothesis that the predictors are jointly insignificant $(p<0.001)$.

Multicollinearity issues were investigated by examining variance inflation factors (VIFs) and condition indices for the predictor variables. Near multicollinearity is a problem if VIF is greater than 10 (Hayter 1996) or the maximum condition index (CI) for the model is greater than 30 (Myers 1990). An analysis of these measures suggested that the coefficients in Model III for all the measures of performance were biased by near multicollinearity. The VIF for misfit and lambda were greater than 10. The maximum CI for the model was also greater than 30 , and the variance proportions associated with the index suggested that the dependencies involved variables lambda and misfit. We used the residual regression method (Chung and Charoenwong 1998) to handle multicollinearity and spurious correlations; the residual value of lambda from the regression of lambda on misfit was used in the final regression in Model III for high and low IC.

The coefficient of IC misfit in Model II is negative and significant for all dimensions of satisfaction, thereby providing support for Hypothesis 1. Further, for all dimensions of satisfaction, the coefficient of IC misfit is significantly negative for both low and high IC in Model III, demonstrating that this result is robust to both types of BPO. Finally, in all models except satisfaction with service systematization, we find that the difference between the coefficient of IC misfit for low IC and that for high IC in Model III is negative and significant. This implies the negative impact of underinvestment in IC on reliability is greater than that of overinvestment, thereby providing support for Hypothesis 2. It is likely that Hypothesis 2 is not supported in the model of satisfaction with service systematization because, relative to the other three dimensions of satisfaction, systematization is less important to transformational BPO.

The summary of results and support for our hypotheses is outlined in Table 10.

\section{Discussion of Results}

$\mathrm{BPO}$ has gained momentum as organizations increasingly outsource broader, information-intensive business processes such as human resources, finance, accounting, and customer care to achieve diverse strategic objectives. Consequently, we have widened the conceptualization of outsourcing beyond a simple contractual transaction that reduces transaction costs. We extended the basis of design and management of the BPO relationship from potential exchange hazards to IR of the BPO relationship and the form of relational design from the governance structure that addresses exchange hazards to IC of the exchange that address the IR of the relationship. We examine IR of the BPO relationship as predicted by the complexity and interdependencies of the outsourced process and IC of the BPO relationship as comprising the underlying governance structure, relational processes, and information technologies.

We find that analyzability, variety, and interdependence of the outsourced process explain significant variance in the observed IR of the BPO relationship. It is likely that the user firm will process information to address additional factors including appropriation concerns resulting from behavioral and environmental uncertainty. Further, in the model of IC choice, the insignificance of the user firm's outsourcing experience and prior association between the firms, once we introduced the measure for IR, suggests that these variables may capture the effects of underlying IR. While it may be difficult to isolate the observed IR attributable to each of these variables, in considering the IR of the BPO relationship predicted by outsourced process attributes, we empirically demonstrate the distinct role of the information intensiveness of the outsourced process in guiding the choice of IC. This enables us to separate the impact of IR, as theorized by the IPV, from that of constructs of mutual trust and environmental uncertainty, theorized in the institutional economics literature.

The results of the structural model confirm that differences in IC across BPO relationships are manifest in differences in the underlying governance structure, relational processes, and technologies. Further, the finding of positive covariance between these dimensions, although not direct evidence of complementarity, has important implications for future research in this area. Governance structures and relational processes in interorganizational exchanges have long been treated as competing theoretical constructs with little conceptual or empirical insights into how they relate to each other. However, more recent research (e.g., Gulati and Nickerson 2006; Poppo and Zenger 2002) has begun to consider possible complementarities between these constructs and their joint impact on exchange performance. Our support 
Table 6. Estimates for Second Stage Models of Satisfaction with Service Reliability

\begin{tabular}{|c|c|c|c|c|}
\hline \multirow{2}{*}{$\begin{array}{c}\text { Independent } \\
\text { Variables }\end{array}$} & \multirow[b]{2}{*}{ Model I } & \multirow[b]{2}{*}{ Model II } & \multicolumn{2}{|c|}{ Model III } \\
\hline & & & High IC & Low IC \\
\hline Firm Size & $0.209^{* * *}$ & 0.125 & 0.146 & 0.208 \\
\hline Firm Tenure & -0.000 & 0.051 & -0.017 & $0.375^{\star \star \star}$ \\
\hline Prior Association & $0.213^{\star \star}$ & $0.206^{\star \star}$ & $0.240^{\star *}$ & -0.031 \\
\hline Uncertainty & $-0.188^{\star \star}$ & $-0.231^{\star \star}$ & $-0.302^{\star \star \star}$ & 0.151 \\
\hline Experience & $0.295^{\star \star}$ & $0.258^{\star \star \star}$ & 0.086 & $0.572^{\star \star \star}$ \\
\hline IC & 0.0005 & 0.080 & & \\
\hline IC Misfit & & $-0.351^{* * *}$ & $-0.319^{* \star}$ & $-0.627^{\star \star * *}$ \\
\hline Retail & -0.028 & -0.033 & -0.048 & 0.072 \\
\hline Financial & -0.040 & -0.013 & -0.045 & 0.060 \\
\hline Correction for self-selection $(\lambda)$ & & -0.011 & -0.157 & 0.337 \\
\hline $\mathrm{N}$ & 127 & 127 & 86 & 41 \\
\hline Model F & $5.96^{\star \star \star}$ & $7.03^{\star \star \star}$ & $5.97^{\star \star \star}$ & $3.34^{* * *}$ \\
\hline Adjusted $\mathrm{R}^{2}$ & 0.24 & 0.32 & 0.35 & 0.35 \\
\hline
\end{tabular}

${ }^{\star} p<0.10 ;{ }^{* \star} p<0.05 ;{ }^{* \star} p<0.01$

\section{Table 7. Estimates for Second Stage Models of Satisfaction with Service Responsiveness}

\begin{tabular}{|c|c|c|c|c|}
\hline \multirow{2}{*}{$\begin{array}{c}\text { Independent } \\
\text { Variables }\end{array}$} & \multirow[b]{2}{*}{ Model I } & \multirow[b]{2}{*}{ Model II } & \multicolumn{2}{|c|}{ Model III } \\
\hline & & & High IC & Low IC \\
\hline Firm Size & 0.127 & 0.010 & 0.143 & 0.055 \\
\hline Firm Tenure & 0.020 & 0.068 & -0.042 & 0.092 \\
\hline Prior Association & $0.342^{\star \star \star}$ & $0.322^{\star \star \star}$ & $0.207^{\star \star}$ & 0.197 \\
\hline Uncertainty & -0.051 & -0.119 & -0.089 & -0.081 \\
\hline Experience & $0.269^{\star \star \star}$ & $0.212^{\star \star}$ & $0.196^{*}$ & -0.038 \\
\hline IC & 0.100 & 0.254 & & \\
\hline IC Misfit & & $-0.407^{\star \star \star}$ & $-0.298^{* \star}$ & $-0.557^{\star \star \star \star}$ \\
\hline Retail & 0.034 & 0.020 & -0.038 & 0.201 \\
\hline Financial Services & -0.028 & 0.004 & -0.030 & 0.150 \\
\hline Correction for self-selection $(\lambda)$ & & 0.044 & -0.533 & $-1.182^{\star \star}$ \\
\hline $\mathrm{N}$ & 127 & 127 & 86 & 41 \\
\hline Model F & $6.40^{\star \star \star}$ & $8.45^{\star \star \star}$ & $6.11^{\star \star \star}$ & 4.49 \\
\hline Adjusted $\mathrm{R}^{2}$ & 0.26 & 0.37 & 0.35 & 0.44 \\
\hline
\end{tabular}

${ }^{*} p<0.10 ;{ }^{* \star} p<0.05 ;{ }^{* \star} p<0.01$ 


\section{Table 8. Estimates for Second Stage Models of Satisfaction with Service Systematization}

\begin{tabular}{|c|c|c|c|c|}
\hline \multirow{2}{*}{$\begin{array}{l}\text { Independent } \\
\text { Variables }\end{array}$} & \multirow[b]{2}{*}{ Model I } & \multirow[b]{2}{*}{ Model II } & \multicolumn{2}{|c|}{ Model III } \\
\hline & & & High IC & Low IC \\
\hline Firm Size & -0.006 & -0.113 & 0.002 & -0.012 \\
\hline Firm Tenure & -0.028 & -0.009 & -0.104 & 0.043 \\
\hline Prior Association & $0.389^{* \star *}$ & $0.358^{\star \star \star}$ & $0.227^{\star \star}$ & $0.296^{*}$ \\
\hline Uncertainty & 0.063 & -0.008 & -0.045 & 0.189 \\
\hline Experience & $0.251^{* \star \star}$ & $0.194^{\star *}$ & 0.121 & 0.069 \\
\hline IC & 0.104 & 0.300 & & \\
\hline IC Misfit & & $-0.273^{\star \star *}$ & $-0.271^{*}$ & $-0.408^{*}$ \\
\hline Retail & -0.045 & -0.066 & -0.110 & 0.043 \\
\hline Financial Services & $-0.138^{*}$ & -0.115 & -0.097 & -0.123 \\
\hline Correction for self-selection $(\lambda)$ & & -0.064 & $-0.712^{\star \star}$ & -0.856 \\
\hline $\mathrm{N}$ & 127 & 127 & 86 & 41 \\
\hline Model F & $6.78^{\star \star \star}$ & $6.81^{\star \star \star}$ & $4.92^{\star \star \star}$ & $3.16^{\star \star \star}$ \\
\hline Adjusted $\mathrm{R}^{2}$ & 0.27 & 0.32 & 0.29 & 0.33 \\
\hline
\end{tabular}

${ }^{*} p<0.10 ;{ }^{* *} p<0.05 ;{ }^{* \star} p<0.01$

Table 9. Estimates for Second Stage Models of Satisfaction with Service Innovation

\begin{tabular}{|c|c|c|c|c|}
\hline \multirow{2}{*}{$\begin{array}{l}\text { Independent } \\
\text { Variables }\end{array}$} & \multirow[b]{2}{*}{ Model I } & \multirow[b]{2}{*}{ Model II } & \multicolumn{2}{|c|}{ Model III } \\
\hline & & & High IC & Low IC \\
\hline Firm Size & $0.227^{\star \star \star}$ & 0.082 & 0.164 & 0.279 \\
\hline Firm Tenure & 0.046 & 0.082 & -0.034 & $0.324^{*}$ \\
\hline Prior Association & $0.282^{\star \star \star}$ & $0.247^{\star \star \star}$ & $0.200^{\star \star}$ & 0.123 \\
\hline Uncertainty & $-0.159^{* * *}$ & $-0.251^{* \star \star}$ & $-0.216^{\star \star}$ & -0.004 \\
\hline Experience & $0.238^{\star \star \star}$ & $0.163^{\star \star}$ & 0.065 & 0.238 \\
\hline IC & 0.100 & $0.326^{* *}$ & & \\
\hline IC Misfit & & $-0.412^{\star \star \star}$ & $-0.389^{\star \star \star}$ & $-0.640^{\star \star \star}$ \\
\hline Retail & $-0.141^{*}$ & $-0.164^{\star \star}$ & $-0.171^{\star *}$ & -0.068 \\
\hline Financial Services & $-0.159^{\star \star}$ & $-0.125^{\star}$ & -0.098 & -0.159 \\
\hline Correction for self-selection $(\lambda)$ & & -0.040 & $-0.683^{\star \star}$ & -0.047 \\
\hline $\mathrm{N}$ & 127 & 127 & 86 & 41 \\
\hline Model F & $9.30^{\star \star \star}$ & $12.04^{\star \star \star}$ & $9.49^{\star \star \star}$ & $3.46^{\star \star \star}$ \\
\hline Adjusted $R^{2}$ & 0.35 & 0.47 & 0.47 & 0.36 \\
\hline
\end{tabular}

${ }^{*} p<0.10 ;{ }^{* *} p<0.05 ;{ }^{* \star *} p<0.01$

Table 10. Summary of Support for Hypotheses

\begin{tabular}{|l|c|c|c|c|}
\hline & $\begin{array}{c}\text { Satisfaction with } \\
\text { Reliability }\end{array}$ & $\begin{array}{c}\text { Satisfaction with } \\
\text { Responsiveness }\end{array}$ & $\begin{array}{c}\text { Satisfaction with } \\
\text { Systematization }\end{array}$ & $\begin{array}{c}\text { Satisfaction with } \\
\text { Process Innovation }\end{array}$ \\
\hline Hypothesis 1 & Supported & Supported & Supported & Supported \\
\hline Hypothesis 2 & Supported & Supported & Not Supported & Supported \\
\hline
\end{tabular}


for an integrated latent representation of governance structure and relational processes contributes to this literature and suggests that the joint assessment of these constructs is necessary to enhance the explanatory power of extant theories of organization. The conceptualization of IC also extends transaction cost analyses beyond traditional considerations of incentive conflict. It suggests that governance structures differ not only in their ability to align incentives between the user firm and the service provider but also in their ability to provide a framework for coordination and information processing across firm boundaries.

Our finding that the choice between low or high IC levels is influenced significantly by the IR of the BPO relationship enhances our claim that the two classes of BPO relationships should incorporate distinctive types of IC. This distinction is robust and theoretically relevant to future research on BPO. For instance, future studies can examine the extent to which there may be differences among the three dimensionsgovernance structure, relational processes, and technologieswithin each of these categories. We believe that clusters of these three attributes will help in the development of richer typologies of BPO relationships.

The integrated representation of IC for transformational BPO initiatives also provides a conceptualization of the partnership construct for use in future research. Dibbern et al. (2004), in their review of the IS outsourcing literature, note that outsourcing partnerships are variously defined as the sharing of risks and rewards (Fitzgerald and Willcocks 1994), the development of long-term relationships (Klepper 1995), and in terms of attributes of user firm-service provider interactions such as trust and communication (Grover et al. 1996). Further, these conceptualizations of outsourcing partnerships do not examine the underlying contractual structure, suggesting that their results must be interpreted cautiously (Grover et al. 1996). For example, Lacity and Hirschheim (1993) find that outsourcing relationships, often portrayed as a strategic partnership in the literature, are at odds with the actual outsourcing contract. The support for an integrated representation of IC in transformational BPO emphasizes that outsourcing partnerships comprise not only tight relational processes, but also complementary hierarchical contracts and sophisticated coordination technologies.

An important finding in this study is that performance differences across BPO relationships arise as a function of the fit (or lack of) between the IR and IC of the relationship. This result is robust to both classes of BPO relationshipstransactional and transformational-and to all measures of satisfaction with service (1) reliability, (2) responsiveness, (3) innovation, and (4) systematization. This suggests that absent a holistic strategy for value capture that pays close attention to the unique nature of the outsourced task, BPO initiatives can create a significant dent in firm competitiveness. In the case of transformational BPO, aligned IC provide critical coordination capabilities while in the case of transactional BPO, aligned IC enable effective utilization of managerial effort to enhance efficiency of the outsourced process.

Our result regarding the adverse influence of misfit on performance helps resolve conflicting findings in the literature (Dibbern et al. 2004) involving the impact of partnerships on exchange performance. For instance, Grover et al. (1996) conclude that the establishment of elements of partnership such as trust and communication are important determinants of outsourcing success. However, Lacity and Hirschheim (1993) find that viewing a relationship as a partnership can be dangerous because it may lead to a loose or incomplete contract, in part because the client thinks of the outsourcing vendor as a partner when in fact it is not, thereby engendering appropriation concerns. This study emphasizes that the effectiveness of investments in partnership structures is contingent on the nature of the underlying outsourced task; such investments are beneficial when the underlying task is complex and marked by interdependencies, yet they are costly and inefficient when the task is simple and modular.

In addition to supporting the overall positive impact of fit between IR and IC on performance, this study finds that misfit between IR and IC in transformational BPO initiatives results in significantly higher levels of dissatisfaction with service reliability, responsiveness, and innovation than transactional BPO. However, the two classes of relationships do not differ in terms of satisfaction with service systematization. This result is consistent with differing impact and expectations across the two classes of BPO relationships. Although transactional BPO initiatives may engender steady improvements in operational efficiency through reduction of process errors, they do not generate competitive advantage since there is nothing idiosyncratic about the exchange relationship. On the other hand, transformational BPO initiatives enable participant firms to uniquely combine, exchange, or invest in idiosyncratic assets, thereby realizing relational rents and competitive advantage. Thus, when the expectation to "out innovate" is not met in these relationships, dissatisfaction is pronounced. Further, in transformational BPO, the negative impact of the inability to reliably execute the process or respond to dynamic business requirements is widely felt in the user firm. Our results suggest that underinvestment in IC does not impact standard procedures that enable seamless service provision. Rather, they impede achieving the greatest benefits from outsourcing. In our study, these benefits 
translate to higher levels of reliability, responsiveness, and process innovation.

The study has important implications for BPO practice as well. Industry surveys find that many firms are strongly dissatisfied with BPO agreements, and that many do not expect any cost savings to materialize. This study identifies key issues that determine positive business outcomes in BPO and outlines a holistic strategy that helps achieve these outcomes.

\section{Conclusion}

Our study adds to the literature on firm boundaries, and emphasizes that as outsourcing matures to being a collaborative network paradigm that is increasingly strategic in its impact, attention must be paid to issues of work design and coordination. We empirically demonstrate that the extent to which firms can accurately predict their IR of control and coordination and design IC that are aligned with such IR is an important determinant of their ability to leverage BPO.

The central role of IR in BPO relationships may be investigated more closely. Given that an understanding of IR is important for the efficient design of information mechanisms and coordination capabilities in outsourcing relationships, the IR of the BPO relationship may well influence the fundamental choice of firm boundaries. Thus, future research could examine the role of IR as an important basis for why firms exist. Further, while in this study we conceptualize IR in terms of the amount of information that must be processed to address the complexity and interdependencies of the outsourced process, future studies may explicitly examine other important aspects of information requirements such as quality and visibility, and how the choice of IC in the BPO relationship addresses these requirements.

This study is subject to certain limitations. First, it treats IR of the BPO relationship as an exogenous construct. However, in a continuous feedback system marked by important learning processes, the user firm will likely adjust IR and its antecedents to better align with the IC of the relationship. This may give rise to an endogeneity issue, which results in inconsistent OLS estimates. The results of Hausman's specification test for endogeneity of IR in our model indicate that OLS produces consistent estimates and is efficient. It is likely that endogeneity does not impact our results because learning effects develop over longer periods of time. However, it is important to recognize that as the goals and expectations of the user firm and provider evolve with time, the IR and IC of the BPO relationship also evolve as does their relationship. In the current study, we have only cross-sectional data, which limits our ability to provide a richer conceptualization of the relationship between IR and IC. A multiperiod model will address this issue and introduce a dynamic perspective that examines how governance forms change over time with evolving expectations and goals of participant firms.

Second, our measure of observed IR does not consider the amount of information processed by the service provider. However, our use of regression scores for IR, predicted by the attributes of the outsourced process, helps address this issue, since IR is measured at the process level and not at the firm level. Further, as a robustness check, we measure the IR of service providers for a subsample of outsourcing dyads. The correlation between the two measures of IR was greater than 0.60 , suggesting that the two information sets were mutually consistent.

Third, we do not consider objective measures of efficiency recorded in service level agreements (SLAs) in the contract. However, given the nascent and topical nature of BPO, such data are difficult to obtain from user firms for reasons of confidentiality. Further, given the heterogeneity in BPO objectives (for instance, innovation versus cost savings), allied strategic importance of the outsourced processes, and ensuing timeline of returns from outsourcing, it is difficult to reconcile BPO contracts and SLAs in terms of a singular measure of performance. Thus, our measures of service satisfaction create defined anchor points and represent the best alternative. Yet, future research must consider performance outcomes that reflect the unique nature of the BPO engagement. This is especially true as BPO matures, engendering substantial and sustainable transformation in firm performance (Linder 2004).

Despite these limitations, we believe that this study makes important contributions to the literature on the organization of outsourcing relationships. Comprehensive data on transaction and relational characteristics of a range of BPO relationships allows us to take an early step toward understanding the drivers of performance of this rapidly growing form of outsourcing relationships. The results yield an important understanding of the value of BPO and are useful to user firms for designing relationships with the service provider. This, in turn, enables the user firm and the provider to define and enact clear expectations that impact competitiveness.

\section{Acknowledgments}

The authors thank Cynthia Beath, Rajeev Sharma, and Marshall Scott Poole for helpful comments on earlier versions of this 
manuscript. We also wish to acknowledge the helpful comments provided by seminar participants at the 2005 International Conference on Information Systems, the 2006 Big XII MIS Conference, and Information Systems research seminars at the University of Texas at Austin, University of Arizona at Tucson, and Arizona State University. Any errors remain the responsibility of the authors.

\section{References}

Agarwal, R., and Lucas, H. C., Jr. 2005. "The Information Systems Identity Crisis: Focusing on High-Visibility and High-Impact Research," MIS Quarterly (29:3), pp. 381-398.

Anand, B., and Khanna, T. 2000. "Do Firms Learn to Create Value? The Case of Alliances," Strategic Management Journal (21:3), pp. 295-315.

Anderson, J. C., and Narus, J. A. 1990. "A Model of Distributor Firm and Manufacturer Firm Working Partnerships," Journal of Marketing (54), pp. 42-58.

Argyres, N. 1999. "The Impact of Information Technology on Coordination: Evidence from the B-2 'Stealth' Bomber.," Organization Science (10:2), pp. 162-180.

Argyres, N. S., and Liebeskind, J. P. 1999. "Contractual Commitments, Bargaining Power, and Governance Inseparability: Incorporating History into Transaction Cost Theory," Academy of Management Review (24), pp. 49-63.

Armstrong J. S., and Overton, T. 1977. "Estimating Nonresponse Bias in Mail Surveys," Journal of Marketing Research (14), pp. 396-402.

Aron R., and Singh J. 2003. "IT Enabled Strategic Outsourcing: Knowledge Intensive Firms, Information Work and the Extended Organizational Form," Working Paper, Operations and Information Management Department, Wharton School, University of Pennsylvania (http://knowledge.wharton.upenn.edu/papers/1071. pdf).

Aundhe, M. D. 2003. "Information Logistics Issues in Outsourced Knowledge Operations," Working Paper, T. A. Pai Management Institute, Manipal, Karnataka, India.

Bagozzi, R. P., Yi, Y., and Phillips, L. W. 1991. "Assessing Construct Validity in Organizational Research," Administrative Science Quarterly (36), pp. 421-458.

Baker, W. E. 1990. "Market Networks and Corporate Behavior," American Journal of Sociology (6:3), pp. 589-625.

Barber, M. B., and Venkatraman, M. 1986. "The Determinants of Satisfaction for a High Envelopment Product: Three Rival Hypotheses and Their Implications in the Health Care Context," Advances in Consumer Research (13), pp. 317-320.

Bensaou, M., and Venkatraman, N. 1995. "Configurations of Interorganizational Relationships: A Comparison Between U.S. and Japanese Automakers," Management Science (41:9), pp. 1471-1492.

Bloch, M., and Lempres, E. C. 2008. "From Internal Service Provider to Strategic Partner: An Interview with the Head of Global Business Services at P\&G," McKinsey Quarterly, July (http:// www.mckinseyquarterly.com/From_internal_service_provider
_to_strategic_partner_An_interview_with_the_head_of_Globa 1_Business_Se).

Borman, M. 2006. "Applying Multiple Perspectives to the BPO Decision: A Case Study of Call Centres in Australia," Journal of Information Technology (21:2), pp. 99-115.

Chung, K. H., and Charoenwong, C. 1998. "Insider Trading and the Bid-Ask Spread," The Financial Review (33), pp. 1-20.

Daft, R. L., and Lengel, R. H. 1986. "Organizational Information Requirements: Media Richness and Structural Design," Management Science (32:5), pp. 554-571.

Daft, R. L., and Macintosh, N. B. 1981. "A Tentative Exploration into the Amount and Equivocality of Information Processing in Organizational Work Units," Administrative Science Quarterly (26), pp. 207-224.

Daft, R. L., and Weick, K. E. 1984. "Toward a Model of Organizations as Interpretation Systems," Academy of Management Review (9:2), pp. 284-295.

Davenport, T., and Short, J. 1990. "The New Industrial Engineering: Information Technology and Business Process ReDesign," Sloan Management Review (31:4), pp. 11-27.

Dibbern, J., Goles, T., Hirschheim, R., and Jayatilaka, B. 2004. "Information Systems Outsourcing: A Survey and Analysis of the Literature," Communications of the ACM (35:4), pp. 6-102.

Dyer, J. H., and Singh, H. 1998. "The Relational View: Cooperative Strategy and Sources of Interorganizational Competitive Advantage," Academy of Management Review (23:4), pp. 660-679.

Fehr E., and Gachter, S. 2000. "Do Incentive Contracts Crowd Out Voluntary Cooperation?," Working Paper No. 34, Institute for Empirical Research in Economics, University of Zurich.

Fitzgerald, G., and Willcocks, L. 1994. "Relationships in Outsourcing: Contracts and Partnerships," in Proceedings of the Second European Conference on Information Systems, W. J. Baets (ed.), Nijenrode, The Netherlands, May 30-31, pp. 55-66.

Galbraith, J. R. 1973. Designing Complex Organizations, Reading, MA: Addison-Wesley.

Gardner, J., and Cooper, M. C. 1988. "Elements of Strategic Partnership," in Partnerships: A Natural Evolution in Logistics Relationships, J. E. McKeon (ed.), Cleveland, OH: Logistics Research, Inc., pp. 15-32.

Ghoshal, S., and Moran, P. 1996. "Bad for Fractice: A Critique of the Transaction Cost Theory," Academy of Management Review (21), pp. 13-47.

Grover, V., Cheon, M. J., and Teng, J. T. C. 1996. "The Effect of Service Quality and Partnership on the Outsourcing of Information Systems Functions," Journal of Management Information Systems (12:4), pp. 89-116.

Geanakoplos, J. 1992. “Common Knowledge," Journal of Economic Perspectives (6), pp. 53-82.

Gulati, R., Lawrence, P. R., and Puranam, P. 2005. "Adaptation in Vertical Relationships: Beyond Incentive Conflict," Strategic Management Journal (26), pp. 415-440.

Gulati, R., and Nickerson, J. A. 2006. "Inter-Organizational Trust, Governance Choice, and Exchange Performance," working paper, Olin School of Business, Washington University, St. Louis, MO. 
Gulati, R., and Singh, H. 1998. "The Architecture of Cooperation: Managing Coordination Costs and Appropriation Concerns in Strategic Alliances," Administrative Science Quarterly (43), pp. 781-814.

Hayter, A. 1996. Probability and Statistics for Engineers and Scientists, Boston: PWS Publishing Co.

Heath, C., and Staudenmayer, N. 2000. "Coordination Neglect: How Lay Theories of Organizing Complicate Coordination in Organizations," in Research in Organizational Behavior, B. M. Staw and N. Staudenmayer (eds.), Greenwich, CT: JAI Press, pp. 153-191.

Heckman, J. 1979. "Sample Selection Bias as a Specification Error," Econometrica (47:1), pp. 153-161.

Heide, J. B., and John, G. 1990. "Alliances in Industrial Purchasing: The Determinants of Joint Action in Buyer-Seller Relationships," Journal of Marketing Research (27:1), pp. 24-36.

Henderson, R. M., and Cockburn, I. 1994. "Measuring Competence? Exploring Firm Effects in Drug Discovery," Strategic Management Journal (15), pp. 63-84.

Hipp, C., and Grupp, H. 2005. "Innovation in the Service Sector: The Demand for Service-Specific Innovation Measurement Concepts and Typologies," Research Policy (34:4), pp. 517-535.

Hirschheim, R., Dibbern, J., and Heinzl, A. 2008. "Foreword to the Special Issue in IS Sourcing," Information Systems Frontiers (10), pp. 125-127.

Hirschheim, R. A., and Lacity, M. C. 2000. "The Myths and Realities of Information Technology Insourcing," Communications of the ACM (43:2), pp. 99-107.

Jacobides, M. G. 2005. "Industry Change Through Vertical Disintegration: How and Why Markets Emerge," Academy of Management Journal (48:3), pp. 465-498.

Keller, R. T. 1994. "Technology-Information Processing Fit and the Performance of R\&D Project Groups: A Test of Contingency Theory," Academy of Management Journal (37:1), pp. 167-179.

Kern, T. 1997. "The Gestalt of an Information Technology Outsourcing Relationship: An Exploratory Analysis," in Proceedings of the $18^{\text {th }}$ International Conference on Information Systems, K. Kumar and J. I. DeGross (eds), Atlanta, GA, December 15-17, pp. 37-58.

Klepper, R. 1995. "The Management of Partnering Development in Information Systems Outsourcing," Journal of Information Technology (10), pp. 249-258.

Lacity, M., and Hirschheim, R. 1993. Information Systems Outsourcing: Myths, Metaphors and Realities, Chichester, England: Wiley.

Lacity, M., and Willcocks, L. 2001. Global Information Technology Outsourcing: Search for Business Advantage, Chichester, England: Wiley.

Lee, J., Miranda, S. M., and Kim, Y. 2004. "IT Outsourcing Strategies: Universalistic, Contingency, and Configurational Explanations of Success," Information Systems Research (15:2), pp. 110-131.

Leiblein, M. J., Reuer, J. J., and Dalsace, F. 2002. "Do Make or Buy Decisions Matter? The Influence of Organizational Governance on Technological Performance," Strategic Management Journal (23:9), pp. 817-833.
Linder, J. C. 2004. "Transformational Outsourcing," Sloan Management Review (45:2), pp. 52-58.

Linder, J. C., Cantrell, S., and Crist, S. 2002. "Business Process Outsourcing Big Bang: Creating Value in an Expanding Universe," white paper, Accenture Institute for Strategic Change, Cambridge, MA, July.

Marcolin, B. L., and McLellan, K. L. 1998. "Effective IT Outsourcing Arrangements," in Proceedings of the $31^{s t}$ Annual Hawaii International Conference on System Sciences, Los Alamitos, CA: IEEE Computer Society Press, pp. 654-665.

Masten, S. E., Meehan, W., and Snyder, E. A. 1991. "The Costs of Organization," Journal of Law, Economics and Organization (7:1), pp. 1-25.

McCann, J., and Galbraith, J. R. 1981. "Interdepartmental Relations," in Handbook of Organizational Design, Volume I, P. C. Nystrom and W. H. Starbuck (eds.), New York: Oxford University Press, pp. 60-84.

Monteverde, K. 1995. “Technical Dialog as an Incentive for Vertical Integration in the Semiconductor Industry," Management Science (41:10), pp. 1624-1638.

Myers, R. H. 1990. Classical and Modern Regression with Applications, Boston: PWS-Kent Publishing Company.

Oliver, R. L., Rust, R. T., and Varki, S. 1997. "Customer Delight: Foundations, Findings, and Managerial Insight," Journal of Retailing (73), pp. 311-336.

Parasuraman, A., Zeithaml, V. A., and Berry, L. L. 1985. “A Conceptual Model of Service Quality and its Implications for Future Research," Journal of Marketing (49:4), pp. 41-50.

Pavlou, P. A., Liang, H., and Xue, Y. 2007. "Understanding and Mitigating Uncertainty in Online Exchange Relationships: A Principal-Agent Perspective," MIS Quarterly (31:1), pp. 105-136.

Pentland, B. T. 2003. "Sequential Variety in Work Processes," Organization Science (14:5), pp. 528-540.

Perrow, C. 1967. "A Framework for the Comparative Analysis of Organizations," American Sociological Review (32), pp. 194-208.

Podsakoff, P. M., MacKenzie, S. B., Lee, J.-Y., and Podsakoff, N. P. 2003. "Common Method Biases in Behavioral Research: A Critical Review of the Literature and Recommended Remedies," Journal of Applied Psychology (88:5), pp. 879-903.

Poppo, L., and Zenger, T. 2002. "Do Formal Contracts and Relational Governance Function as Substitutes or Complements?," Strategic Management Journal (23), pp. 707-725.

Puranam, P., and Gulati, R. 2005. "The Social and Contractual Structure of Vertical Relationships," Strategic and International Management Working Paper.

Ring, P., and Van de Ven, A. 1992. "Developmental Processes of Cooperative Interorganizational Relationships," Academy of Management Review (19:1), pp. 90-118.

Rouse, A. C., and Corbitt, B. J. 2006. "Business Process Outsourcing: The Hysteresis Effect and Other Lessons," in Information Systems Outsourcing: Enduring Themes. New Perspectives and Global Challenges, R. Hirschheim, A. Heinzl, and J. Dibbern (eds.), New York: Springer, pp. 583-602. 
Segars, A. H., and Grover, V. 1998. "Strategic Information Systems Planning: An Investigation of the Construct and its Measurement," MIS Quarterly (22:2), pp. 139-163.

Stinchcombe, A. L. 1985. "Contracts as Hierarchical Documents," in Organization Theory and Project Management, A. Stinchcombe and C. Heimer (eds.), Oslo: Norwegian University Press, pp. 121-171.

Sundaramurthy, C., and Lewis, M. 2003. "Control and Collaboration: Paradoxes of Governance," Academy of Management Review (28:3), pp. 337-415.

Sureshchandar, G. S., Rajendran, C., and Anantharaman, R N. 2002. "The Relationship Between Service Quality and Customer Satisfaction: A Factor Specific Approach," Journal of Services Marketing (16:4), pp. 363-379.

Tornbohm, C. 2006. "Include the CIO When Planning BPO," Gartner Research, July.

Tushman, M. L., and Nadler, D. A. 1978. "Information Processing as an Integrating Concept in Organizational Design," Academy of Management Review (3:3), pp. 613-624.

Uzzi, B. 1997. "Social Structure and Competition in Inter-Firm Networks: The Paradox of Embeddedness," Administrative Science Quarterly (42:1), pp. 35-67.

Uzzi, B., and Lancaster, R. 2003. "Relational Embeddedness and Learning: The Case of Bank Loan Managers and Their Clients," Management Science (49:4), pp. 383-399.

Vázquez, L. 2007. "Determinants of Contract Length in Franchise Contracts," Economics Letters (97:2), pp. 145-150.

Venkatraman, N. 1989. "The Concept of Fit in Strategy Research: Toward Verbal and Statistical Correspondence," Academy of Management Review (14:3), pp. 423-444.

von Hippel, E. 1994. “'Sticky Information' and the Locus of Problem Solving: Implications for Innovation," Management Science (40:4), pp. 429-439.

Whitaker, J., Kumar, S., and Krishnan, M. S. 2006. "Performance Outcomes of Onshore and Offshore Business Process Outsourcing," in INFORMS Conference on Information Systems and Technology, Pittsburgh, PA, November 4-5.

Willcocks, L. P., and Kern, T. 1998. "IT Outsourcing as Strategic Partnering: The Case of the UK Inland Revenue," European Journal of Information Systems (7:1), pp. 29-45.

Williamson, O. E. 1991. "Comparative Economic Organization: The Analysis of Discrete Structural Alternatives," Administrative Science Quarterly (36), pp. 269-296.
Withey, M., Daft, R. L., and Cooper, W. H. 1983. "Measures of Perrow's Work Unit Technology: An Empirical Assessment and a New Scale," Academy of Management Journal (26:1), pp. 45-63.

Wüllenweber, K., Beimborn, D., Weitzel, T., and König, W. 2008. "The Impact of Process Standardization on Business Process Outsourcing Success," Information Systems Frontiers (10:2), pp. 211-224.

Zuboff, S. 1988. In the Age of the Smart Machine: The Future of Work and Power, New York: Basic Books.

\section{About the Authors}

Deepa Mani is an assistant professor at the Indian School of Business. Her research interests are at the intersection of technology, organization, and firm value, including studying the nature of technological advances, the organizational capabilities created, and management interventions required of these advances, and the ultimate impact of these emergent organizational capabilities on firm performance.

Anitesh Barua is a professor at the McCombs School of Business, the University of Texas at Austin. His research interests include assessing the business value of IT investments, electronic business transformation, and governance of business process outsourcing relationships. His research articles have appeared in journals such as Information Systems Research, MIS Quarterly, Organization Science, and Sloan Management Review.

Andrew Whinston is the Hugh Roy Cullen Centennial Chair in Business Administration, Professor of Information Systems, Computer Science and Economics, and Director of the Center for Research in E-Commerce (CREC) in McCombs School of Business at the University of Texas at Austin. He has published over 300 papers in leading academic journals in economics, information systems, and computer science, and received the LEO Award for Lifetime Exceptional Achievement in Information Systems in 2005. He is the editor of Decision Support Systems and Journal of Organizational Computing and Electronic Commerce and has been on the editorial boards of several major IS journals. 